\title{
Aplicação de Medida Socioeducativa de Semiliberdade para Adolescentes nos Contextos do Brasil e de Portugal
}

\author{
Daniele Dalla Porta \\ Universidade Federal de Santa Maria, RS, Brasil \\ Amanda Schöffel Sehn \\ Universidade Federal do Rio Grande do Sul, Porto Alegre, RS, Brasil
}

Aline Cardoso Siqueira*

Universidade Federal de Santa Maria, Santa Maria, RS, Brasil

\begin{abstract}
RESUMO
O comportamento infrator e a aplicação de medida socioeducativa na adolescência representam uma dimensão relevante de estudo. O presente artigo visou conhecer as características de duas instituições que atendem adolescentes em conflito com a lei. Trata-se de uma pesquisa qualitativa e exploratória, na qual foram realizadas entrevistas semiestruturadas com 44 adolescentes, que cumpriam medida socioeducativa em regime semiaberto em Portugal e no Brasil. A partir da análise de conteúdo, verificou-se que as instituições pesquisadas diferem em seus modelos de funcionamento e regras internas, bem como nas oportunidades oferecidas aos meninos. Estes aspectos refletem as diferenças culturais, socioeconômicas e jurídicas desses países. Entretanto, ambas as instituições possibilitam a ocorrência de processos proximais, favorecendo o desenvolvimento dos adolescentes.
\end{abstract}

Palavras-chave: adolescentes infratores; medida socioeducativa; semiliberdade; instituição.

\begin{abstract}
The Semi Liberty Measure Application to Adolescents in the Context of Brazil and Portugal

The delinquent behavior in childhood and adolescence and the socio-educational measure application represent a relevant dimension of study. This article aimed to know the characteristics of two institutions that attend adolescents with law conflict. This is a qualitative and exploratory research, in which semi-structured interviews was performed with 44 adolescents, who fulfill socioeducative measure in a semi-open regime of Portugal and Brazil. As a result it was found that the surveyed institutions differ in their internal operating models and rules, as well as the opportunities that are offered to adolescents. These aspects show the cultural, socio-economic and legal differences between these countries. However, both allow the occurrence of proximal processes leading to the development of adolescents.
\end{abstract}

Keywords: young offenders; socio-educational measures; semi-liberty; institution.

As instituições que recebem adolescentes em conflito com a lei apresentam propostas para resgatar o jovem e estão presentes em diversos contextos e culturas, representando uma dimensão relevante de estudo na atualidade. Em um levantamento realizado em 2004 no Brasil, foi identificado que 39.578 adolescentes estavam inseridos no sistema socioeducativo, um número que inclui o conjunto de todos os regimes (aberto, semiaberto e fechado) (Conselho Nacional dos Direitos da Criança e do Adolescente,
CONANDA, 2006). Já no ano de 2011, este número aumentou expressivamente, totalizando 89.245 adolescentes inseridos também nos três regimes (Brasil, 2011). Em relação às medidas socioeducativas, tem-se que a semiliberdade é a modalidade menos utilizada no Brasil, representando apenas $8 \%$ das medidas aplicadas no contexto brasileiro (CONANDA, 2006). Em Portugal, os registros de 1983 apontam que 893 jovens estavam em instituições tutelares, enquanto em 2013 houve um decréscimo nesse número, caindo para

* Endereço para correspondência: Aline Cardoso Siqueira - alinecsiq@gmail.com 
251 o número de meninos cumprindo medida (Direção Geral da Política de Justiça, DGPJ, Pordata, 2013).

Diversos estudos têm descrito o envolvimento de adolescentes com atos delitivos. Nesse sentido, ressaltam-se os que investigaram o significado da medida para adolescentes em privação de liberdade (Souza \& Costa, 2012), a trajetória de vida dos adolescentes anteriormente ao cumprimento da medida (Muller, Barboza, Oliveira, Santos, \& Paludo, 2009; Sehn, Dalla Porta \& Siqueira, 2015), e após medida socioeducativa de internação (Nardi \& Dell'Aglio, 2014). Também se destacam as produções científicas relacionadas aos laços familiares dos adolescentes (Gallo \& Williams, 2008; Zappe \& Dias, 2012b), aos projetos de vida (Jacobina \& Costa, 2007; Marcelino, 2006; Nardi, Jahn, Dell'Aglio, 2014) e aos fatores de risco e proteção (Costa \& Assis, 2006; Gallo \& Williams, 2008; Nardi \& Dell'Aglio, 2010). No entanto, verifica-se uma lacuna na literatura científica quanto aos estudos que investigam as instituições em que os adolescentes cumprem as medidas socioeducativas, especialmente no contexto brasileiro (Azevedo, 2013; Manso \& Almeida, 2009; Neves, 2007).

$\mathrm{O}$ ingresso do adolescente em contexto institucional de privação de liberdade caracteriza uma transição ecológica, na qual a posição da pessoa no ambiente é alterada em função de uma mudança de papel (Bronfenbrenner, 1979/1996). Nesse sentido, o cumprimento de medida socioeducativa em instituições de semiliberdade e/ou privação de liberdade pode influenciar os adolescentes e trazer implicações para o ambiente ecológico dos mesmos. Para tanto, o presente artigo visa conhecer as características das instituições que atendem adolescentes que cumprem medida socioeducativa em semiliberdade, traçando um contraponto entre a realidade brasileira e portuguesa.

No atinente aos contextos citados, a saber, Brasil e Portugal, cabe destacar que se trata de duas realidades distintas nos aspectos socioeconômicos, culturais e em termos jurídicos e de intervenção social. Quanto ao Brasil, ressalta-se que o país está em desenvolvimento, com estratégias recentes na área do comportamento infrator, enquanto Portugal, é considerado um país desenvolvido, com políticas relativas à delinquência estruturadas há mais tempo. Apesar dessas diferenças, investigar regimes semelhantes, mas com propostas distintas permite repensar as políticas que permeiam as instituições de semiliberdade. E assim, possibilitar novas estratégias que contribuam para a efetividade da aplicação das medidas, e consequentemente, que ofereçam melhores oportunidades aos adolescentes.

\section{Especificidades da medida socioeducativa e a teoria bioecológica}

A infração da lei na adolescência é a conduta que corresponde no Código Penal ao crime ou à contravenção. Quando isso ocorre são aplicadas medidas socioeducativas, as quais podem ser definidas como o conjunto de respostas e de intervenções institucionais e legais em relação a adolescentes que cometem infrações e se encontram em situação de risco (Muniz, 2008). De acordo com o Estatuto da Criança e do Adolescente (Brasil, 1990), os adolescentes brasileiros, autores de atos infracionais, recebem a aplicação de medidas socioeducativas, considerando o início da responsabilidade penal aos 18 anos. As medidas possuem um caráter socioeducativo e protetivo, com o intuito de resgatar e reintegrar o jovem na sociedade mediante procedimentos pedagógicos que desenvolvam a sua capacidade intelectual, profissional e o seu retorno ao convívio familiar (Cavalcante, 2008). As diretrizes que orientam a aplicação da medida visam tornar o adolescente mais autônomo e solidário, e também melhorar o seu relacionamento interpessoal, para que não reincida na prática delitiva (Brasil, 2005). Ainda, buscam favorecer o acesso do adolescente às oportunidades de superação de sua situação de exclusão, através da garantia de direitos fundamentais; assim como, a ressignificação e a formação de valores para a participação na vida em sociedade, por meio da preservação de vínculos sociais e comunitários (Brasil, 2005).

No Brasil também se destaca o Plano Individual de Atendimento (PIA) com os adolescentes e suas famílias ao término da medida, o qual visa traçar metas viáveis que auxiliem os adolescentes a repensar suas trajetórias, desvinculadas do ato infracional. Outra estratégia dirigida ao egresso é o Programa de Oportunidades e Direitos (POD), o qual foi instituído através do projeto de Lei $n^{\circ} 295 / 2008$, e tem como finalidade auxiliar a inserção familiar, educacional e profissional do adolescente e do jovem adulto egresso de instituição de privação de liberdade. Entretanto, a adesão ao programa é voluntária, assim como o número de vagas é restrito. Nesse sentido, estudo realizado por Nardi e Dell'Aglio (2014), que teve como objeti- 
vo investigar trajetórias de adolescentes brasileiros após cumprimento de medida socioeducativa de internação, apontou que o acompanhamento dos adolescentes egressos das instituições de privação de liberdade é frágil, tendo em vista que dos 143 adolescentes pesquisados, as autoras não conseguiram obter dados a respeito da trajetória de 54 adolescentes.

Em Portugal, a legislação fixa em 16 anos a maioridade penal, sendo os adolescentes, autores de atos infracionais, amparados pela Lei de Protecção de Crianças e Jovens em Perigo (Lei $\mathrm{n}^{\circ}$ 147/99, Portugal, 1999), bem como pela Lei Tutelar Educativa (Lei $n^{\circ}$ 166/99, Portugal, 1999). Nesse contexto, a medida socioeducativa não tem como finalidade a punição, mas a educação para o direito, para que o jovem interiorize as normas e os valores sociais do dever-ser jurídico, a qual se complementa com a finalidade da inserção, de forma digna e responsável, na vida em comunidade (Manso \& Almeida, 2009; Portugal, 2012; Torres, 2010). Os métodos de intervenção na delinquência são caracterizados pela adoção de medidas centradas no adolescente infrator, visando a uma modificação do comportamento traduzido no retorno a uma situação de adaptação social (Negreiros, 2001). Nesse sentido, a medida socioeducativa também cumpre uma função socializadora (Azevedo, 2013).

Na realidade portuguesa também se salienta o Projeto Educativo Pessoal (PEP), o qual é construído 30 dias após a entrada do jovem na instituição e descreve a intervenção planejada para o período de internamento. $\mathrm{O}$ adolescente pode participar da elaboração desse documento, assim como pode haver alteração ao longo do período da medida, conforme o comportamento do interno. Ressalta-se que não foram encontrados projetos e/ou programas que preveem o acompanhamento dos adolescentes após o término da medida socioeducativa.

O período de cumprimento da medida socioeducativa deve se constituir em um momento para a estruturação de um projeto de vida e de laços sociais (Nardi, Jahn, \& Dell'Aglio, 2014; Sehn, Dalla Porta, \& Siqueira, 2015). Para tanto, os adolescentes necessitam do apoio de figuras representativas que os encorajem a buscar por caminhos mais saudáveis, os quais incluam principalmente o trabalho e o estudo, como forma de reinserção na sociedade (Costa \& Assis, 2006; Gallo \& Williams, 2008; Sehn, Dalla Porta, \& Siqueira, 2015). Estudos portugueses com jovens que cumpri- ram medida apontaram como um dos resultados a ressignificação da inserção social e familiar do adolescente e o entendimento de que a internação cumpriu uma função educadora e sancionadora (Manso \& Almeida, 2009).

A relação que é estabelecida entre o adolescente e os ambientes com os quais ele interage durante o período que cumpre medida socioeducativa, pode favorecer o desencadeamento de processos proximais, ou seja, de relações próximas que o afetam e são afetadas por ele (Bronfenbrenner \& Morris, 1998). O engajamento e a interação em uma atividade são aspectos necessários para que ocorra um processo proximal, assim como o período de tempo prolongado e estável. Além disso, deve haver reciprocidade entre as relações interpessoais para que o adolescente possa perpetuar esse processo mesmo na ausência dessas pessoas (Bronfenbrenner, 1979/1996).

As formas como as relações são estabelecidas na instituição também dependem do equilíbrio de poder, ou seja, da distribuição de poder na relação. Entende-se que uma situação ótima para a aprendizagem e desenvolvimento é aquela em que o equilíbrio do poder gradualmente é alterado em favor da pessoa em desenvolvimento; bem como auxilia a pessoa a lidar com relações de poder diferenciais (Bronfenbrenner, 1979/ 1996). Nesse sentido destaca-se o estudo realizado por Gaspar (2013), que investigou as transições de adultos e jovens adultos que viveram em Lares de Infância e Juventude em Portugal. Dentre os resultados, o autor aponta para a importância da distribuição de poderes por parte da direção, equipe técnica e pedagógica da instituição, considerando o processo de amadurecimento e o desenvolvimento de competência dos jovens. Assim, a instituição durante o cumprimento da medida socioeducativa, consiste em um ambiente ecológico importante ao adolescente, no qual ele pode ressignificar suas vivências e, a partir disso, estabelecer relações positivas que favoreçam o desenvolvimento.

\section{Caracterização das instituições de semiliberdade}

Conforme o Estatuto da Criança e do Adolescente (Brasil, 1990), a privação de liberdade é aplicada em situações de extrema gravidade, nas quais não há outra medida mais adequada ao caso, quando não há reiteração no cometimento de delitos graves ou por descumprimento de medida determinada anteriormente. 
Na aplicação da medida, estão subjacentes os princípios de brevidade, excepcionalidade e respeito à condição peculiar de pessoa em desenvolvimento (Brasil, 2005). O internamento é proposto no Brasil em dois regimes: no semiaberto e no fechado. No primeiro, a semiliberdade é uma alternativa, com caráter socioeducativo e protetivo, que priva, parcialmente, o adolescente da liberdade e concomitantemente o coloca em contato com a comunidade (Brasil, 1990; Cavalcante, 2008). Ainda, a semiliberdade pode ser determinada como medida inicial ou como forma de transição para o meio aberto. $\mathrm{O}$ adolescente que cumpre esse regime permanece sob a custódia estatal, estando submetido às regras de uma unidade educacional (Brasil, 2005).

A legislação portuguesa também propõe a institucionalização devido à gravidade do crime cometido, sendo a medida aplicada quando a intervenção em meio comunitário se torna ineficiente ou inviável (Portugal, 2012). O internamento ocorre nos três regimes: aberto, semiaberto e fechado e é executado em centro educativo classificado com o correspondente regime de funcionamento e grau de abertura ao exterior. Em relação à semiliberdade, o adolescente é institucionalizado nesse regime quando tiver cometido fato qualificado, definido como crime contra as pessoas, ou cometido dois ou mais fatos qualificados e que correspondam a pena máxima no Código Penal português (Portugal, 1999).

Ambas as instituições que acolhem os jovens em regime semiaberto apresentam um sistema de normas que regulamentam as relações entre os indivíduos e definem como essas relações devem ser (Scott, 1995). No Brasil, o funcionamento da instituição propõe a participação do adolescente em atividades externas à Unidade (Brasil, 2006). Além disso, o Centro de Atendimento em Semiliberdade é regido por algumas regras, entre elas o respeito aos horários das atividades propostas, bem como aos horários de saída e de retorno e a responsabilidade por parte dos adolescentes pela organização e limpeza da casa (Brasil, 2006). A rotina dos adolescentes inclui estudo e trabalho diurno de segunda a quinta-feira, período em que dormem na instituição, sendo que aos finais de semana o jovem retorna para sua casa, desde que autorizado pela coordenação da Unidade de Semiliberdade (Brasil, 2006).

Quanto à rotina dos Centros Educativos de Portugal, a Lei Tutelar Educativa (Portugal, 1999) prevê que os adolescentes que estão cumprindo medida de internamento no regime semiaberto residam na instituição e frequentem atividades escolares, educativas, desportivas, de orientação vocacional e de formação profissional no estabelecimento. Os adolescentes também podem ser autorizados a realizar essas atividades no meio externo, desde que contemple o previsto no Projeto Educativo Pessoal. Ademais, podem sair sem acompanhante mediante autorização, bem como passar os finais de semana e as férias com os familiares ou responsáveis legais. Desse modo, a intervenção em centro educativo obedece a um regulamento geral, embora alguns aspectos institucionais sejam regulamentados por um regime disciplinar interno (Portugal, 1999).

Em relação às instituições de internamento portuguesas, estudo etnográfico realizado por Neves (2007) evidenciou que o tempo é contínuo, regulado e imposto ao adolescente, por meio de rotina preestabelecida. Além disso, não leva em consideração a escolha dos internos, sendo as atividades de caráter obrigatório. O autor também discute o caráter fechado da instituição portuguesa, o qual pode ser caracterizado, de acordo com Goffman (2005), pela barreira existente na relação social com o mundo externo e o impedimento de sair, muitas vezes, presente também na estrutura física em forma de portas fechadas, paredes altas, grades e guardas.

A partir do exposto acerca do funcionamento institucional, observa-se que, apesar de tratar sobre o mesmo tipo de regime, a saber, o semiaberto, cada instituição possui especificidades de acordo com as realidades pesquisadas. Ainda, destaca-se que as estratégias utilizadas por ambas as instituições diferem principalmente quanto à abertura em relação ao meio externo. Em que no Brasil há maior possibilidade do adolescente transitar no meio social, enquanto em Portugal a maioria das atividades fica restrita ao ambiente interno, apesar da lei assegurar o contato com o exterior. Nesse sentido, ressalta-se que estão sendo pesquisadas duas instituições específicas, tendo em vista que estas podem diferir de outras situadas no mesmo país, pois cada instituição, além de ser regida pelas leis federais, possui um regulamento interno específico.

Considerando os apontamentos teóricos, tem-se que a instituição cumpre papel fundamental na reinserção do jovem na sociedade e na ressignificação do 
ato infracional. Assim, o objetivo deste artigo é conhecer as características das instituições que atendem adolescentes portugueses e brasileiros, que cumprem medida socioeducativa em semiliberdade, como a rotina institucional, as regras de funcionamento e a percepção dos adolescentes sobre a instituição.

\section{MÉTODO}

\section{Delineamento e participantes}

O presente artigo é recorte de uma pesquisa mais abrangente de caráter comparativo, exploratório e de cunho qualitativo (Turato, 2003). Participaram desse estudo 44 adolescentes, do sexo masculino, sendo 22 brasileiros e 22 portugueses, com idades entre 12 e 20 anos, os quais cumpriam medida socioeducativa em semiliberdade em um Centro Educativo localizado em Portugal e no Centro de Atendimento em Semiliberdade de uma cidade do interior do Rio Grande do Sul. Para a delimitação etária da adolescência, utilizou-se o critério do Ministério da Saúde (2005) que entende esta fase como o período de vida compreendido entre a faixa etária de 10 a 19 anos. Considerando que a delimitação dessa fase é flexível, foi incluído um jovem de 20 anos que estava cumprindo medida sob proteção das leis voltadas para crianças e adolescentes.

A amostra foi constituída por conveniência, sendo que todos os meninos que cumpriam medida em ambas as instituições foram convidados para participar do estudo. Os dados da instituição portuguesa foram coletados primeiramente e armazenados em um banco de dados. Dessa forma, igualou-se o número de sujeitos pesquisados no Brasil à amostra já coletada em Portugal. Foram utilizados códigos para facilitar a análise do material, sendo assim, para os dados referentes ao Brasil utilizaram-se as siglas de S1 a S22, já para os dados portugueses de S23 a S44.

\section{Instrumento}

Para a realização do presente estudo foram utilizadas entrevistas semiestruturadas com eixos norteadores. A entrevista foi utilizada para conhecer a rotina institucional dos adolescentes, explorar a percepção sobre a instituição e refletir sobre as diferenças do funcionamento das instituições que acolhem adolescentes em conflito com a lei no Brasil e em Portugal. Alguns eixos norteadores utilizados para guiar a entrevista foram: "Percepção sobre as medidas socioe- ducativas", "Função da instituição na vida dos adolescentes" "Oportunidades encontradas na instituição", entre outros.

\section{Procedimentos e considerações éticas}

Este projeto de pesquisa foi desenvolvido em duas etapas. A primeira delas ocorreu durante o período de mobilidade acadêmica das duas primeiras autoras na Universidade do Porto (UP), Portugal. O projeto foi desenvolvido, submetido e aprovado pelo Ministério da Justiça de Portugal, em Lisboa, seguindo os trâmites prescritos pelo país. Com a autorização, deu-se início à coleta de dados em Portugal. Já no Brasil, as autoras encaminharam o projeto ao Comitê de Ética em pesquisa com seres humanos da Universidade Federal de Santa Maria, o qual foi aprovado sob o número 271.370/2013, considerando os preceitos éticos preconizados pela Resolução 466/12 do Conselho Nacional da Saúde (Brasil, 2012). Além disso, o projeto foi aprovado e autorizado pela direção da Fundação de Atendimento Socioeducativo no Brasil e pelo Centro Educativo Santo Antônio em Portugal, instituições que acolhem adolescentes em situação de privação de liberdade. Apesar de executarem a mesma medida de proteção de semiliberdade, as instituições não são equivalentes especialmente por estarem inseridas em contextos socioeconômico e social distinto. Os adolescentes foram convidados a participar da pesquisa, sendo esclarecidos acerca dos objetivos, do caráter sigiloso e voluntário do estudo, bem como da confidencialidade dos dados. Foram assegurados todos os direitos dos entrevistados, assim como foi pontuado aos participantes que estes não teriam nenhum risco ou benefício direto, além de contribuir para o aperfeiçoamento da ciência sobre o tema em questão. Foi solicitada a assinatura do Termo de Consentimento Livre e Esclarecido aos adolescentes brasileiros e portugueses que aceitaram participar da pesquisa.

A coleta de dados, em Portugal, ocorreu entre os meses de fevereiro a março de 2012, e no Brasil, entre os meses de julho a outubro de 2013. Todas as entrevistas foram realizadas pelas duas primeiras autoras, gravadas e posteriormente transcritas. Mais especificamente, em Portugal as entrevistas foram realizadas em uma sala na instituição, no entanto, um agente da unidade permanecia do lado externo da porta durante a realização das entrevistas. Já no Brasil, as entrevistas também ocorreram na instituição, em uma sala disponibilizada pela assistente social. 
Os adolescentes foram convidados a participar da pesquisa, sendo esclarecidos acerca dos objetivos, do caráter sigiloso e voluntário do estudo, bem como da confidencialidade dos dados. Foram assegurados todos os direitos dos entrevistados, assim como foi pontuado aos participantes que estes não teriam nenhum risco ou benefício direto, além de contribuir para o aperfeiçoamento da ciência sobre o tema em questão. Foi solicitada a assinatura do Termo de Consentimento Livre e Esclarecido aos adolescentes brasileiros e portugueses que aceitaram participar da pesquisa.

\section{Análise dos dados}

A análise do material foi feita a partir da análise de conteúdo (Bardin, 1977), através do desmembramento do texto em unidades, em categorias segundo reagrupamentos analógicos. No presente artigo serão enfatizadas as percepções dos adolescentes sobre a instituição e a medida socioeducativa, a partir de dois contextos distintos, a saber, Brasil e Portugal, de acordo com as seguintes categorias: "Tem regras, todo lugar tem regras", "Aí quando vê, eu caí aqui e abriu, abriu uma porta", e "Quando tiram a liberdade, te tiram tudo". A primeira trata das regras estabelecidas na rotina dos adolescentes, enquanto a segunda categoria aborda as oportunidades oferecidas pelas instituições. Por fim, a terceira discorre sobre o que estar privado de liberdade produz no adolescente.

\section{RESULTADOS}

À luz da Teoria Bioecológica, a discussão está pautada nas instituições que executam medida de semiliberdade nos dois países. Sabe-se que tais instituições apresentam funcionamentos distintos, apesar de aplicarem o mesmo tipo de regime e interessa compreender tais diferenças e não as julgar. A partir disso, serão observados os aspectos que favorecem o processo de desenvolvimento do adolescente de acordo com a Teoria Bioecológica (Bronfenbrenner,1979/1996).

\section{"Tem regras, todo lugar tem regras": funcionamento e regras das instituições}

Essa categoria englobou as falas das percepções dos adolescentes quanto ao funcionamento da instituição, tais como: regras, horários, atividades diárias, tanto internas quanto externas, entre outros aspectos. Nesse sentido, para os adolescentes brasileiros a instituição tem sentidos diferentes durante o cumprimento da medida socioeducativa, embora o entendimento acerca das regras estabelecidas seja similar: "Tem regras, todo lugar tem regras, eu acho né. Ah, a regra é dormir, dormir meia noite, mas não tem muita coisa sabe de mais" (S10).

As regras cumprem um papel importante na instituição, já que estabelecem uma forma de funcionamento. E quando a mesma é descumprida, há punição. "Função é do cara obedecê as regra, de obedecê os horário tudo certo, porque se o cara não obedece [...] vai fica de castigo" (S2); "Aqui [...] tu não tá em casa né, mas tá como tu tá em casa, [...], tu pode fazer o que tu quer, entendeu? Tu faz o que tu quer, dentro das regras" ( $\mathrm{S} 18)$.

Os adolescentes demonstraram a vivência do que Bronfenbrenner (1979/1996) nomeou como transição ecológica, a qual provoca mudanças no seu microssistema e mesossistema a partir de novas relações e atividades estabelecidas dentro da instituição, como o relacionamento com os monitores e colegas, ingresso em um trabalho e/ou escola e cursos profissionalizantes. Com o estabelecimento destas novas relações, operam os processos proximais (Bronfenbrenner, 1979/1996), que produzem e sustentam o desenvolvimento. Da mesma forma, ao proporcionar esse espaço ao adolescente, a instituição permite a ele o equilíbrio de poder (Bronfenbrenner, 1979/1996), isto é, o jovem recebe uma oportunidade gradual de exercer controle sobre as situações, adotando uma postura ativa em relação ao ambiente. O mesossistema também é alterado, tendo em vista que consiste no conjunto de microssistemas e nas inter-relações estabelecidas entre eles (Bronfenbrenner, 1979/1996). Dois ou mais microssistemas, como frequentar a escola e as relações estabelecidas na instituição, influenciam a pessoa em desenvolvimento e se interinfluenciam, mesmo não estabelecendo uma relação direta.

Independentemente da forma de organização da instituição, a medida socioeducativa de internamento propõe ao jovem uma nova rotina (Nardi \& Dell'Aglio, 2010). Pode-se perceber que as regras e o funcionamento da instituição são assimilados a partir da rotina, que é distinta entre os adolescentes, já que alguns trabalham e fazem cursos, enquanto outros optam por não realizar este tipo de atividades e acabam com uma parte do tempo em ócio. Volpi (2008) pontua a importância das atividades desenvolvidas pelo adolescente, sendo que os objetivos das mesmas consistem em educar para 
o exercício da cidadania e não somente ocupar o tempo e gastar energia dos internos.

Os aspectos relacionados ao funcionamento, às regras e à rotina da instituição de Portugal são descritos pelos adolescentes como tendo um caráter mais rígido, podendo enquadrar-se em uma instituição total (Goffman, 2005). Observa-se que a instituição impõe atividades para os meninos, que são vigiadas e controladas: "É o tratamento, tipo, sempre a olharem pra nós, sempre a controlar o que nós fazemos, a ouvir sempre as nossas conversas [...] ah aqui também é proibido falar crioulo [...] mal verem que já fala outra língua, ah... carimbado, então eles já mandam pro quarto e dá isso”. (S42).

No regime semiaberto, o adolescente passa por diversas fases, sendo que em cada uma as regras são distintas, com permissões e restrições específicas. As fases são entendidas como progressão da medida, independentemente do regime. Nesse sentido, na medida em que o adolescente progride o comportamento, é beneficiado, como descreve o entrevistado em relação ao uso das roupas pessoais: "Tipo deixar nós usar a nossa roupa, da fase 1 usa [a roupa da instituição]... só a fase 3 a 4 pra cima [que não usa]" (S42). E também quanto às regras de convivência: "Essas regras de acender a televisão às $8 h[. .$.$] depois não podemos$ ligar a televisão, deitar as 9h que é na fase 1, na fase 2, deita as 9:30, fase 3 deita as 10h, aqui tem muitas regras" (S42).

Os horários das atividades na instituição portuguesa são preestabelecidos, dado também verificado em estudo de Neves (2007), o que reforça as regras. As características desse centro de internamento se aproximam a uma instituição total (Goffman, 2005), no que diz respeito às regras de convivência, a estrutura física, a presença constante de monitores, assim como uma rotina preestabelecida, com horários fixos para as atividades.

As instituições descritas apresentam características distintas, sendo que a instituição brasileira possui um caráter mais permissivo, enquanto o funcionamento da instituição portuguesa denota maior rigidez e controle. Outra diferença explícita entre as instituições é a forma que a rotina é estabelecida. No centro de atendimento, são considerados o desejo e a vontade do adolescente em realizar as tarefas não obrigatórias, como cursos e trabalho. Ao contrário disso, no centro de internamento (Portugal), a maioria das atividades é obrigatória, res- tringindo a possibilidade de escolha do adolescente. Considerando as diferenças existentes entre os funcionamentos institucionais, destaca-se a importância da presença de regras claras em ambos os contextos estudados. A delimitação, daquilo que é permitido ou proibido ao adolescente, poderá contribuir posteriormente para o processo de escolarização, formação profissional e inserção no mercado de trabalho.

\section{"Aí quando vê eu caí aqui e abriu, abriu uma porta": oportunidades oferecidas pelas instituições}

Esta categoria trata das oportunidades oferecidas pela instituição para auxiliar o jovem a construir um projeto de vida e pensar em possibilidades de futuro, durante e após a passagem pela instituição. As oportunidades oferecidas pela Unidade de Semiliberdade foram entendidas pelos adolescentes como uma das funções da instituição durante o cumprimento da medida: "o papel do CASEMI é bota as pessoas, os guris aqui, em sociedade eu acho sabe, dizer pra essa gurizada trabalhar, [...]. Um serviço, com um estudo, mas se a pessoa não quer, ela não quer, não adianta" (S10).

O período que o jovem cumpre a medida pode constituir um momento para a estruturação ou a construção de um projeto de vida, vinculado às oportunidades oferecidas pela instituição. Ao oferecer novas oportunidades, antes não visualizadas pelos adolescentes, a instituição passa a ter um papel organizador e protetivo na vida do jovem (Costa \& Assis, 2006; Nardi, Jahn, \& Dell'Aglio, 2014; Rizzini, Zamora, \& Klein, 2008): “Bá, agora eles tão reestruturando a minha vida né, agora eu vou voltar a estudar, então eu vou correr atrás de um emprego agora" (S16). Do mesmo modo, estudo de Ferreira (2008) com meninos em conflito com a lei, evidenciou o interesse dos adolescentes pelo trabalho lícito, seguido do interesse em estudar, mudar de vida e ajudar a família.

Contudo, nem sempre a orientação pessoal adotada pela pessoa é compatível com o clima de motivação apresentado pelo contexto (Bronfenbrenner, 1979/ 1996). Assim como cada pessoa possui um conjunto de recursos que a capacitam a atuar com maior ou menor grau de eficiência nos contextos em que participa (Bronfenbrenner, 1979/1996). Nesse sentido, a escolha referente às oportunidades oferecidas na instituição - e fora dela - é feita pelo adolescente, que, às 
vezes, pode não entender isso como a melhor opção: "aqui vai pela cabeça de cada um se quer mesmo mudar, procura, sai à procura de um serviço, sai à procura pra mudar de vida, né" (S20).

Em relação ao emprego, os adolescentes mencionaram a importância da legalização do trabalho, possibilitada pela instituição: "trabalhei de servente, bãi trabalhei de tudo, menos de carteira assinada, né" (S12). Outra função que os adolescentes atribuíram ao Centro de Atendimento em Semiliberdade está relacionada ao fortalecimento dos vínculos familiares e ao apoio afetivo oferecido pela equipe técnica da instituição. Segundo Costa e Assis (2006), os adolescentes infratores necessitam do apoio de figuras representativas que os encorajem a buscar por caminhos melhores e mais saudáveis, que incluam principalmente o trabalho e o estudo, como forma de reinserção na sociedade. Isso pode ser ilustrado na fala dos adolescentes: "me ajudaram, me incentivando, [...] eu tava bem ruim, não tava conversando com minhas irmã, tinha brigado, aí chamaram aí, conversemo tudo, aí agora nós tamo bem" (S12).

A semiliberdade não priva totalmente o adolescente do seu direito de ir e vir, oferecendo oportunidades de acesso a serviços e organização da vida cotidiana (Volpi, 2008). Todas as atividades propostas pela instituição, aderindo o adolescente ou não, buscam inseri-lo no meio social, conforme a fala: "é pra ver se eu tô pronto mesmo pra sair pra rua, pra mim não sair mais pra fazer besteira, esse tempo aqui é pra saber conviver no meio das pessoas" (S20).

A instituição de internamento de Portugal oferece possibilidades internas de atividades para os adolescentes, já que estes não têm contato frequente com o meio externo. Além da escola, as oficinas educativas e de formação são exemplos de atividades possíveis aos adolescentes, que podem contribuir para o projeto de vida: "entrei revoltado e vou sair já com outra mentalidade, continuar a escola, arranjar um trabalho, não meter-me em confusões, não roubar" (S37).

A escolarização pode possibilitar aos adolescentes o aprendizado de um conjunto de conhecimentos que colabore com o seu regresso, permanência ou continuidade na rede regular de ensino (Volpi, 2008). Ainda, a possibilidade de concluir o estudo dentro da instituição também está vinculada com um projeto de vida, o qual pode favorecer o desenvolvimento pessoal e social do adolescente (Marcelino, 2006). Nesse sentido, pesquisas apontam que anteriormente ao cumprimento da medida, a maioria dos adolescentes relatou dificuldades e problemas ao frequentar a escola, como repetência e evasão escolar (Muller et al., 2009; Gallo \& Williams, 2008). Do mesmo modo, os adolescentes entrevistados sinalizaram sobre os estudos: "porque lá fora eu nunca era capaz de acabar a escola, nem me concentrar nas aulas" (S26); "acho que é outra oportunidade, recuperar o tempo, o tempo que eu perdi lá fora. Não ter estudado, continuado na escola" (S36).

As oportunidades oferecidas pelas duas instituições são distintas e têm objetivos diferentes. No Brasil é obrigatória a inserção do adolescente no ensino regular para dar continuidade aos estudos. Em relação às atividades opcionais, são oferecidos cursos de qualificação profissional em outras instituições. Além disso, é incentivado que o adolescente tenha uma postura proativa, no que tange a busca pelo seu futuro, o que inclui a procura por um emprego, por exemplo. Todavia, em Portugal, são consideradas atividades obrigatórias do adolescente na instituição o retorno aos estudos e a participação em oficinas. Nesse sentido, aponta-se que no Brasil há uma inserção gradual no adolescente no meio social, incentivando uma atitude proativa do mesmo, com o auxílio da instituição. Já o centro de internamento português enfatiza a construção de uma base sólida para o adolescente, em termos de aprendizado e educação, para ao término da medida, ocorrer a inserção social. Ambas as estratégias buscam proporcionar oportunidades ao adolescente, bem como condições que auxiliam na busca por um futuro saudável.

\section{"Quando tiram a liberdade, te tiram tudo": o que estar privado de liberdade produz para 0 adolescente}

A terceira categoria reuniu as falas dos adolescentes relacionadas aos desdobramentos que a privação de liberdade poderá produzir no jovem, que cumpre medida socioeducativa em semiliberdade. Tem-se que, no regime semiaberto em Portugal, o acesso dos adolescentes ao meio externo é restrito, enquanto no Brasil existe maior abertura em relação ao meio social.

A forma de organização da instituição no que se refere à liberdade permitirá - ou não - ao jovem a possibilidade de lidar com a transição de ambiente (da semiliberdade para a liberdade) e com as circunstâncias de poder. Quando se aplica uma medida de priva- 
ção de liberdade, o jovem encontra-se em uma situação na qual todas as decisões sobre sua vida não são tomadas com sua colaboração. Voltando à condição de criança, o adolescente privado de liberdade deverá aprender paulatinamente a exercer e administrar o poder, para que ele possa, quando estiver em liberdade, tomar decisões positivas e saudáveis.

Ao cumprir medida em regime semiaberto, o adolescente brasileiro está parcialmente privado de liberdade, ou seja, o seu contato com o meio externo é restrito e intermediado pela instituição, o que traz desdobramentos para o jovem: "é que na rua, eu tinha liberdade, saía a hora que eu queria e voltava a hora que eu queria e aqui não" (S21). Também ficou evidente que grande parte dos adolescentes brasileiros que cumpre medida na Unidade de Semiliberdade esteve anteriormente em regime fechado, no Centro de Atendimento Socioeducativo (CASE).

Ao serem questionados sobre o que estar semiprivado de liberdade produz, os adolescentes fizeram referência ao período em que estiveram privados de liberdade. Nesse sentido, os adolescentes sinalizaram: "Aqui tu tá fechado, mas você pode circular ainda pela casa né, você é livre pra fazer o que quiser" (S16). "É porque lá [CASE] tu fica trancado né, numa cela né. Agora aqui tu tem liberdade, tu pode sair pra ir pro colégio, vai trabalha, vai fazer um curso entendeu? [...] Por causa que aqui, o cara aprende que liberdade pro cara é tudo" (S18). Do mesmo modo, estudo realizado por Souza e Costa (2012) teve como objetivo investigar o significado que os adolescentes atribuem à medida socioeducativa. Dentre os resultados, os meninos avaliaram a medida de internação como algo ruim devido à ausência de liberdade e à ociosidade. Sendo assim, o período que o adolescente está fechado, leva-o a uma reflexão acerca da vida, dos atos e do motivo de estar na instituição. Além disso, há uma valorização maior da liberdade pelos adolescentes.

$\mathrm{Na}$ realidade portuguesa o regime semiaberto é aplicado em uma instituição com caráter fechado. Contudo, o contexto português de semiliberdade, bem como os desdobramentos que estar privado de liberdade produzem, são semelhantes aos da instituição de regime fechado no Brasil: "eu acho que é muito mal tá fechado, quando tiram a liberdade, te tiram tudo, não se pode sair daqui de dentro" (S25).

Alguns adolescentes também salientaram que é "ruim ficar fechado" e ainda apontaram que estavam na internação porque fizeram algo contrário à lei, mas não conseguiam refletir ou dar alguma importância a essa medida em suas vidas. Contudo, alguns dos adolescentes entrevistados identificaram benefícios durante o cumprimento da medida: "acho que mudou, tive mais consciência das coisas que faço" (S25); "aqui já penso melhor na vida, roubar não preciso [...] tem sempre aquele lado positivo" (S26). Estudo realizado por Manso e Almeida (2009) visou investigar a representação social de jovens institucionalizados em centro educativo. Dentre os resultados, os meninos revelaram uma concepção ambígua da medida, associando, concomitantemente, uma função punitiva e educativa ao centro educativo.

Os desdobramentos que a aplicação da medida socioeducativa em semiliberdade têm para os adolescentes brasileiros e portugueses diferem na forma em que ocorre a internação nas duas instituições, bem como no funcionamento, nas regras e nas atividades propostas. No Brasil, tem-se uma reinserção social gradual, em que o adolescente participa de atividades obrigatórias no meio social, como frequentar a escola, assim como participar de cursos e ter um trabalho - ambas as atividades com caráter opcional. Contudo, em Portugal, a instituição é organizada com o intuito de impor regras aos adolescentes, que visam promover a internalização das normas sociais e dos valores jurídicos.

A privação de liberdade, proposta ao adolescente no regime semiaberto pela instituição de Portugal, muitas vezes permite ao jovem organizar-se internamente e em suas atividades diárias, características que possivelmente não faziam parte da sua rotina anteriormente. Todavia, no Brasil, a possibilidade de participar novamente da sociedade, permite ao jovem pensar em um projeto de vida e planos para o futuro, já que o adolescente visualiza oportunidades que antes não estavam ao seu alcance.

Assim, na medida socioeducativa, para que haja uma transição ecológica que favoreça o adolescente em prol do desenvolvimento, é importante que a instituição de semiliberdade possibilite ao jovem restabelecer paulatinamente o equilíbrio de poder, para que ele possa, aos poucos, lidar com situações que envolvam cada vez mais porções de poder (Bronfenbrenner, 1979/1996). Considera-se que a transição da ausência de poder para poder total de forma repentina é prejudicial, bem como não possibilitar que o jovem exercite o poder é colocá-lo numa posição infantil. 


\section{DISCUSSÃO}

As investigações acerca das instituições que recebem adolescentes em conflito com a lei têm sido escassas. A maioria dos estudos envolvendo essa população se detém em outros aspectos do comportamento desviante, como trajetória de vida, estrutura familiar, uso e abuso de substâncias, fatores de risco e proteção, entre outros. Sendo assim, as contribuições do presente estudo trazem pontos importantes a serem discutidos.

A transição ecológica vivenciada pelo adolescente ao ingressar em uma instituição de semiliberdade terá um sentido singular, sendo que essa experiência não está relacionada somente a importância atribuída ao ambiente, mas também a maneira como o indivíduo vive e percebe esse ambiente. A partir da forma como o adolescente vivencia a experiência dentro da instituição é que serão estabelecidos processos proximais capazes de auxiliar na ressignificação do ato infracional.

A instituição brasileira propõe aos adolescentes uma rotina, com base em regras internas, entretanto, o jovem tem possibilidade de optar por realizar algumas atividades ou não. Com isso, a instituição supõe que o jovem tem gostos e desejos singulares e a partir disso, espera-se um maior engajamento dos meninos. Em Portugal, a maioria das atividades dos adolescentes são obrigatórias e internas, com horários preestabelecidos. Ao propor uma rotina fixa e estável, a instituição possibilita ao adolescente uma forma de organizar seu cotidiano e suas questões pessoais.

Desse modo, destaca-se que a instituição brasileira incentiva a possibilidade de escolha e a atitude proativa do adolescente ao passo que o centro de internamento português oferece regras mais consistentes. Essas estratégias distintas podem estar atreladas aos contextos sociais e culturais em que os adolescentes estão inseridos. No entanto, ambas as instituições proporcionam aos adolescentes oportunidades que visam à construção de um futuro saudável. Especificamente em relação à instituição portuguesa, propõe-se a oferta de atividades que considerem o interesse dos adolescentes. Enquanto no Brasil, sugere-se o estabelecimento de regras mais consistentes, para que o adolescente não permaneça com a maior parte do tempo em ócio.

As oportunidades que a Unidade de Semiliberdade oferece aos adolescentes visam à reinserção social e ao engajamento do jovem em atividades na sociedade, o que é fundamental, considerando a realidade brasileira. Assim, ao perder o vínculo com o Centro de Atendimento, há possibilidade de os adolescentes continuarem seus estudos, bem como trabalhos e/ou cursos, o que auxilia na construção e continuidade de um projeto de vida. Em Portugal, por sua vez, a reinserção do jovem na comunidade acontece apenas no fim da medida, o que pode dificultar a volta do adolescente ao meio social em que estava inserido anteriormente. Considerando as diferenças culturais entre os países e a forma como cada adolescente vivencia o período de cumprimento da medida, esse estudo propõe mudanças no modelo de internamento português. Isso se deve, pois, o arcabouço teórico sustenta a importância de possibilitar ao jovem um contato maior com a sociedade durante o período da medida. Entende-se que o contato gradual com o meio externo é fundamental, para que a instituição possibilite ao adolescente um poder equilibrado, concedido gradualmente, com o intuito de que ao término da medida, o jovem consiga exercer sua autonomia e poder na sociedade.

A semiliberdade juntamente com as regras impostas pela instituição fazem os adolescentes refletirem a respeito de suas vidas, dos atos cometidos e das possibilidades do futuro. No Brasil, os adolescentes mencionaram que refletiram durante sua internação na instituição fechada, percurso que, na maioria das vezes, antecedeu ao cumprimento da medida no semiaberto. Já em Portugal, por se tratar de uma instituição de caráter total, o adolescente é privado de liberdade no regime semiaberto, o que lhe permite refletir a respeito da sua trajetória.

É fundamental situar que o estudo de dois contextos diferentes envolve questões de âmbito social e cultural. Para tanto, deve haver cuidado ao ampliar os dados da amostra para uma população maior do que a pesquisada, assim como para outros contextos que não foram abordados. Algumas limitações devem ser assinaladas neste estudo, como o caráter transversal da coleta de dados. Ainda, é relevante ressaltar que foram abordados aspectos significativos em relação às instituições que recebem adolescentes que cumprem medida socioeducativa em semiliberdade, porém há aspectos que não foram aprofundados e contemplados, sendo passíveis de futuras investigações. Tais questões se referem à efetividade das medidas socioeducativas, aos regimes aberto e fechado, às taxas de reinserção, entre outros fatores. Sendo assim, é possível pontuar que ambas as instituições possuem aspectos 
que favorecem a ocorrência de processos proximais, levando ao desenvolvimento dos adolescentes, bem como outros fatores que podem ser explorados para que o período de aplicação das medidas socioeducativas seja mais efetivo.

\section{REFERÊNCIAS}

Azevedo, T. N. C. (2013). Institucionalização e Lei Tutelar Educativa: As representações de jovens, profissionais e direção de um Centro Educativo. Dissertação (Mestrado em Psicologia). Universidade do Minho, Braga, Portugal.

Bardin, L (1977). Análise de conteúdo. Lisboa: Edições 70.

Brasil. (1990). Estatuto da Criança e do Adolescente (ECA) - Lei no 8.069, de 13 de julho de 1990. Brasília: Ministério da Justiça.

Brasil. (2005). Documento referencial para o Sistema Nacional de Atendimento Socioeducativo. Brasília: Secretaria de Direitos Humanos.

Brasil. (2005). Saúde integral de adolescentes e jovens: Orientações para a organização de serviços de saúde. Brasília: Ministério da Saúde.

Brasil. (2006). Secretaria Especial dos Direitos Humanos. Sistema Nacional de Atendimento Socioeducativo (SINASE). Brasília: CONANDA.

Brasil. (2011). Secretaria de Direitos Humanos. Levantamento Nacional Atendimento Socioeducativo ao Adolescente em Conflito com a Lei. Brasília-DF.

Brasil. (2012). Ministério da Saúde. Resolução no 466/12 Diretrizes e Normas Regulamentadoras de Pesquisas Envolvendo Seres Humanos. Brasília- DF.

Bronfenbrenner, U. (1996). A ecologia do desenvolvimento humano: experimentos naturais e planejados. Trad. Maria Adriana Veríssimo Veronese. Porto Alegre: Artes Médicas. (Originalmente publicado em 1979)

Bronfenbrenner, U., \& Morris, D. (1998). The Ecology of developmental processes. In W. Damon (Ed), Handbook of child psychology (pp. 993-1027). New York: John Wiley \& Sons.

Cavalcante, P. M. (2008). As medidas socioeducativas impostas ao adolescente infrator segundo o ECA: verso $e$ anverso. Monografia (Especialização em Direito), Universidade de Fortaleza, Fortaleza, Ceará, Brasil.

Conselho Nacional dos Direitos da Criança e do Adolescente (CONANDA). (2006). Resolução $n^{\circ} 105$, de 15 de junho de 2005. Brasília.

Costa, C. R. B. S. F., \& Assis, S. G. (2006). Fatores protetivos a adolescentes em conflito com a lei no contexto socioeducativo. Psicologia e Sociedade, 18(3), 74-81.
Direção Geral da Política de Justiça (DGPJ) /Ministério da Justiça (MJ). (2013). PORDATA, Base de dados Portugal Contemporâneo. Portugal.

Ferreira, E. D. S. (2008). O direito enquanto instrumento de garantia dos direitos fundamentais do adolescente em conflito com a lei. In Secretaria Especial dos Direitos Humanos, Justiça Juvenil sob o marco da proteção integral. [Apostila do Seminário de Justiça Juvenil]. São Paulo: ABMP.

Gallo, A. E., \& Williams, L. C. A. (2008). A escola como fator de proteção à conduta infracional de adolescentes. Cadernos de Pesquisa, 38(133), 51-59. doi: 10.1590/ S0100-15742008000100003

Gaspar, J. P. (2013). Do acolhimento à autonomização: O que dizem adultos que viveram institucionalizados. Breves notas metodológicas. Revista Polêm!ca, 12(1), 7-22.

Goffman, E. (2005). Manicômios, prisões e conventos. São Paulo: Perspectiva.

Jacobina, O. M. P., \& Costa, L. F. (2007). "Para não ser bandido": Trabalho e adolescentes em conflito com a lei. Cadernos de Psicologia Social do Trabalho, 10(2), 95110.

Manso, A., \& Almeida, A. T. (2009). Um Discurso a Duas Vozes: Potencialidades de um Estudo Interpretativo sobre Lei e Institucionalização. Psicologia: Reflexão e Crítica, 22(3), 455-465.

Marcelino, M. Q. S. (2006). Construção do projeto de vida de adolescentes: um estudo das representações sociais (Dissertação de Mestrado). Universidade Federal da Paraíba, João Pessoa, Paraíba, Brasil.

Muller, F., Barboza, P. S., Oliveira, C. C., Santos, R. R. G., \& Paludo, S. S. (2009). Perspectivas de adolescentes em conflito com a lei sobre o delito, a medida de internação e as expectativas futuras. Revista Brasileira Adolescência e Conflitualidade, 1(1), 70-87.

Muniz, A. S. (2008). O adolescente infrator. Retirado em 23 de fevereiro de 2013 de http://www.direitonet.com.br/ artigos/exibir/3987/O-adolescente-infrator

Nardi, F. L., \& Dell'Aglio, D. D. (2010). Delinquência juvenil: uma revisão teórica. Acta Colombiana de Psicología, 13(2), 69-77.

Nardi, F. L., \& Dell'Algio, D. D. (2014). Trajetória de Adolescentes em Conflito com a Lei Após Cumprimento de Medida Socioeducativa em Meio Fechado. Revista Psico, PUCRS, 45(4), 541-550.

Nardi, F. L., Jahn, G. M., \& Dell'Algio, D. D. (2014). Perfil de adolescentes em privação de liberdade: eventos estressores, uso de drogas e expectativas de futuro. Psicologia em Revista, 20(1), 116-137.

Negreiros, J. (2001). Delinquências juvenis: trajetórias, intervenções e prevenção. Notícias editorial, Lisboa, 2001. 
Neves, T. (2007). A defesa institucional numa instituição total: o caso de um centro de internamento de menores delinquentes. Análise Social, 42(185),1021-1039.

Peci, A., Vieira, M. M. F., \& Clegg, S. R. (2006) A Construção do "Real" e Práticas Discursivas: o Poder nos Processos de Institucionaliz(ação). RAC, 10(3), 51-71.

Portugal. (1999). Lei Tutelar Educativa - Lei $n^{\circ} 166 / 99$, de 14 de setembro de 1999. Diário da República (Lisboa, Portugal), 1A(215).

Portugal (2012) Ministério da Justiça. Direcção Geral de Reinserção Social. Plano de atividades DGRS, Lisboa.

Rizzini, I., Zamora, M. H., \& Klein, A. (2008). O adolescente em contexto. In Secretaria Especial dos Direitos Humanos (Ed.), Justiça juvenil sob o marco da proteção integral [Apostila do Seminário de Justiça Juvenil]. São Paulo: ABMP.

Scott, R. W. (1995). Institutions and organizations. Thousand Oaks: Sage.

Sehn, A. S., Dalla Porta, D., \& Siqueira, A. C. (2015). "Tocar a vida para frente": possibilidades de planos para o futuro de adolescentes que cometeram ato infracional. Adolescência \& Saúde, 12(1), 28-34.
Souza, L. A., \& Costa, L. F. (2012) O significado de medidas socioeducativas para adolescentes privados de liberdade. Acta Colombiana de Psicología ,15(2), 87-97.

Torres, R. (2010). Que Educação para o direito? Da Lei Tutelar Educativa à intervenção educativa com delinquentes juvenis. Ousar, Integrar, Revista de Reinserção Social e Prova, 7(1), 35-48.

Turato, E. R. (2003). Tratado da Metodologia da Pesquisa Clínico-qualitativa. Petrópolis: Vozes.

Volpi, M. (Org.). (2008). O adolescente e o ato infracional. 7. ed. São Paulo: Cortez.

Zappe, J. G., \& Dias, A. C. G. (2012b). Violência e fragilidades nas relações familiares: refletindo sobre a situação de adolescentes em conflito com a lei. Estudos de Psicologia, 17(3), 389-395. doi: 10.1590/S1413-294X20120 00300006 .
Recebido em: 10/04/2014 Última alteração em: 30/05/2015 Aceito em: 30/06/2015 